\title{
三INTERESPACCB \\ CATADORES DE RECICLÁVEIS RECICLAM PROCESSOS ORGANIZATIVOS, (RE)SIGNIFICAM O TRABALHO E CONSTROEM UMA NOVA HISTÓRIA
}

\author{
RECYCLABLE COLLECTORS RECYCLE ORGANIZATIONAL PROCESSES, \\ REVALUE THE LABOR AND THEY BUILD A NEW STORY
}

\section{RECOLECTORES DE DESECHOS RECICLABLES RECICLAN PROCESOS ORGANIZATIVOS, RE-DIGNIFICAN EL TRABAJO Y CONSTRUYEN UNA NUEVA HISTORIA}

\begin{abstract}
Renata Siviero Martins
Mestra em Educação pela Faculdade de Educação da Universidade do Estado de Minas Gerais FaE/CBH/UEMG. Foi bolsista CAPES. Especialista em Análise Institucional e Esquizoanálise pela Fundação Educacional Lucas Machado. renatasivieromartins@gmail.com

\section{Carlúcia Maria Silva}

Pós-doutora pelo Programa de Pós-graduação em Psicologia Social da Universidade Federal de Minas Gerais - UFMG. Doutora e Mestra em Ciências Sociais pela Pontifícia Universidade Católica de Minas Gerais - PUC Minas. Docente da Universidade do Estado de Minas Gerais -

$\mathrm{FaPP} / \mathrm{CBH} / \mathrm{UEMG}$. carlucia.maria@gmail.com

Recebido para avaliação em 30/01/2017; Aceito para publicação em 31/10/2017.

\section{RESUMO}

A Economia Popular Solidária recobre uma realidade marcada pela heterogeneidade e diversidade. Nessas iniciativas populares subsiste uma tensão fundamental entre o possível e o desejável e carregam consigo a dupla tarefa de superar os limites colocados pela ordem econômica vigente e avançar na construção de novos parâmetros de organização e articulação. O presente trabalho analisa a experiência de catadores de recicláveis do Projeto Novo Ciclo. Além de uma breve introdução e as considerações finais, o artigo apresenta percepções acerca do conceito de Economia Popular Solidária e discute a participação dos catadores de recicláveis na gestão dos resíduos sólidos. Algumas percepções e reflexões sobre a experiência de catadores de recicláveis do Projeto Novo Ciclo, subsidiam o confronto teórico-prático, ou seja, o conceito de economia popular solidária e a experiência desses trabalhadores da reciclagem. A metodologia utilizada consistiu na observação direta e observação participante, além da presença e intervenções nos eventos realizados. Os resultados, ainda parciais, apontam que as atividades realizadas possibilitaram a implantação e fortalecimento de programas de coleta seletiva solidária em municípios da região sul e sudoeste de Minas Gerais. Apontam também o aprimoramento da formação de catadores e de técnicos gestores públicos municipais da Região, bem como ações voltadas para a educação ambiental e mobilização social. Ações e intervenções que resultaram na criação da rede de comercialização de material reciclável denominada Rede Sul Sudoeste MG.
\end{abstract}

Palavras-chave: Economia Popular Solidária; Catadores de Recicláveis; Projeto Novo Ciclo; Participação e Cidadania.

\section{ABSTRACT}


| Renata Siviero Martins | Carlúcia Maria Silva |

The Popular Solidarity Economy reveals a reality marked by heterogeneity and diversity. In these popular initiatives there is a fundamental tension between the possible and the desirable and it carries with the double task of overcoming the limits established by the current economic order and moving forward in the construction of new parameters of organization and articulation. This paper analyzes the experience of recyclable waste collectors of the New Cycle Project. In addition to a brief introduction and the final considerations, the article presents the perceptions about the concept of Popular Solidarity Economy and discusses the participation of recyclable waste collectors in the management of solid waste. Some perceptions and reflections about the experience of recyclable waste collectors of the New Cycle Project, favor the theoretical-practical confrontation, that is, the concept of popular solidarity economy and the experience of these recycling workers. The methodology used consisted of the direct observation and participant observation, besides of the presence and interventions in the events held. The partial results indicate that the carried out activities allowed the implementation and strengthening of selective and solidarity collection programs in municipalities of the south and southwestern region of Minas Gerais. It was also possible to improve the training of collectors and municipal public management technicians in the Region, with actions aimed at environmental education and social mobilization. The actions and interventions led to the creation of a network of commercialization of recyclable materials denominated South Southwest MG Network.

Keywords: Popular Solidarity Economy; Recyclable Waste Collectors; New Cycle Project; Participation and Citizenship.

\section{RESUMEN}

La Economía Popular Solidaria revela una realidad marcada por la heterogeneidad y diversidad. En esas iniciativas populares subsiste una tensión fundamental entre lo posible y lo deseable y carga consigo la doble tarea de superar los límites establecidos por el orden económico actual y el de avanzar en la construcción de nuevos parámetros de organización y articulación. El presente trabajo analiza la experiencia de los recolectores de desechos reciclables del Proyecto Nuevo Ciclo. Además de una breve introducción y las consideraciones finales, el artículo presenta las percepciones acerca del concepto de Economía Solidaria y se discute acerca de la participación de los recolectores de desechos reciclables en la gestión de los residuos sólidos. Algunas percepciones y reflexiones sobre la experiencia de recolectores de desechos reciclables del Proyecto Nuevo Ciclo, favorecen la confrontación teórico-práctica, o sea, el concepto de economía popular solidaria y la experiencia de esos trabajadores del reciclaje. La metodología utilizada consistió en la observación directa y observación participante, además de la presencia e intervenciones en los eventos realizados. Los resultados parciales, señalan que las actividades realizadas posibilitaron la implementación y fortalecimiento de programas de colecta selectiva y solidaria en municipios de la región sur y suroeste de Minas Gerais. Se logró también mejorar la formación de recolectores y de técnicos gestores públicos de la Región, con acciones dirigidas a la educación ambiental y la movilización social. Las acciones e intervenciones condujeron a la creación de una red de comercialización de materiales reciclables denominada Red Sur Suroeste MG.

Palabras clave: Economía Popular Solidaria; Recolectores de Desechos Reciclables; Proyecto Nuevo Ciclo; Participación y Ciudadanía.

\section{INTRODUÇÃO}

A Economia Popular Solidária recobre uma realidade marcada pela heterogeneidade e diversidade. Nessas iniciativas populares subsiste uma tensão fundamental entre o possível e o desejável e carregam consigo a dupla tarefa de superar os limites colocados pela ordem econômica vigente e avançar na construção de novos parâmetros de 
| Catadores de recicláveis reciclam processos organizativos, (re)significam o trabalho e constroem uma nova história|

| Renata Siviero Martins | Carlúcia Maria Silva |

organização e articulação. O público dos empreendimentos econômicos solidários geralmente é composto por mulheres pobres com baixa qualificação, mães chefes de família, com idades bem variadas. Uma parcela significativa da população historicamente excluída do mercado formal de trabalho.

Nesse universo tão complexo, agentes mediadores e atores sociais da economia popular solidária buscam nas atividades econômicas articular solidariedade e práticas de reciprocidade. A produção e desenvolvimento da atividade econômica têm uma dimensão comunitária em que necessidades (demandas) e saberes (competências) estão intimamente articulados tanto no plano local quanto institucional, por meio do reconhecimento pelo poder público, deste "saber popular" e o apoio técnico. Ao evidenciar a complexidade de fatores em jogo nesse emaranhado de contradições e dilemas, ocorrem diferentes olhares e leituras sobre a realidade da economia solidária.

Barbosa (2007, p. 21) argumenta que o termo economia solidária traz consigo uma “controversa teórica" porque apresenta duas imprecisões: supõe segmentos diferenciados e autônomos de economia e a classificação por um dos segmentos como solidariedade, numa sociedade capitalista com seus valores e objetivos distintos. No entendimento da autora, a economia solidária se vincula à "desobrigação pública com a oferta de emprego e à fragilização dos sindicatos e ganha expressão nas periferias das cidades e na zona rural do país a partir da ação direta de igrejas, sindicatos e organizações não governamentais”. O trabalho associado aparece como resposta à nova sociabilidade imposta pelo capital, envolvendo segmentos de trabalhadores desde os mais vulnerabilizados com a baixa escolarização e qualificação e que nunca interagem no mercado de trabalho formal, até trabalhadores desempregados que se submetem ao trabalho precarizados pela via do autoemprego. Ainda nesta mesma reflexão Barbosa (2007, p. 23) aponta para o descomprometimento do Estado, no que se refere à universalização dos direitos, a começar pelo direito ao trabalho assalariado e suas garantias sociais e chama atenção ao que ela denomina de "autonomização civil", que tem como lema "a sociedade por conta própria". Para os estudiosos desta temática, as iniciativas solidárias vivem simultaneamente um momento de profusão e debilidade. No entanto, paradoxalmente, sinalizam também as potencialidades que se fazem presentes nesta "outra economia".

O presente trabalho analisa a experiência do Projeto Novo Ciclo. Além de uma breve introdução e as considerações finais, o artigo apresenta percepções acerca do conceito de Economia Popular Solidária e discute a participação dos catadores de recicláveis na gestão dos resíduos sólidos em municípios da região do Sul e Sudoeste de 
| Catadores de recicláveis reciclam processos organizativos, (re)significam o trabalho e constroem uma nova história|

| Renata Siviero Martins | Carlúcia Maria Silva |

Minas Gerais. Percepções e reflexões sobre a experiência de catadores de recicláveis do Projeto Novo Ciclo, confrontando o conceito de economia popular solidária e a experiência desses trabalhadores da reciclagem.

Os resultados, ainda parciais, apontam que as atividades realizadas possibilitaram a implantação e fortalecimento de programas de coleta seletiva solidária. Apontam também a capacitação de catadores e de técnicos gestores públicos municipais da Região, bem como ações voltadas para a educação ambiental e mobilização social. Ações e intervenções que resultaram na criação da rede de comercialização de material reciclável denominada Rede Sul Sudoeste MG.

O conjunto das ações realizadas representou um passo estratégico para consolidação de processos organizativos de catadores da Região e fortalecimento de organizações de catadores de materiais recicláveis envolvidos, no que diz respeito às suas lutas, aprendizados e perspectivas. Experiências e vivências que apontam para o fortalecimento da formação humana desses sujeitos, que a partir do trabalho associado, tomam consciência de suas ações no campo pessoal e coletivo, compreendem a dimensão sociopolítica de sua organização e articulação e a consciência enquanto sujeito político e protagonistas de uma nova história ainda em construção.

\section{OLHARES E PERCEPÇÕES ACERCA DA ECONOMIA POPULAR SOLIDÁRIA}

O conceito de Economia Solidária, segundo Gaiger (2000a), é ainda processo em construção. São diversos os conceitos e nomes dados a essas iniciativas econômicas solidárias: socioeconomia solidária, economia popular solidária, economia do trabalho, empresas autogestionárias, novo cooperativismo, investimento ético, empresa social, redes de consumo solidário e outros tantos. Fenômenos que, segundo Cattani (2003), correspondem simultaneamente a dimensões concretas e abstratas e não correspondentes à economia conforme a prática capitalista impõe.

Luiz Inácio Gaiger, por sua vez, entende a economia solidária como um conjunto de atividades heterogêneas, nas quais os empreendimentos buscam integrar eficiência e viabilidade bem como o aprimoramento dos princípios cooperativos e democráticos. Nesta reflexão, argumenta Gaiger (2000b, p. 177) que, “autonomia de gestão como atitude de responsabilidade e envolvimento social, conjugando a obtenção de resultados econômicos com outros benefícios” são elementos essenciais (GAIGER, 2000b, p. 177).

Para Gabriel Kraychete, essas iniciativas, também denominadas de economia dos 
| Catadores de recicláveis reciclam processos organizativos, (re)significam o trabalho e constroem uma nova história|

| Renata Siviero Martins | Carlúcia Maria Silva |

setores populares, possuem uma racionalidade econômica ancorada na geração de recursos (monetários ou não), cuja destinação visa prover e repor os meios de vida, bem como a utilização de recursos humanos próprios, agregados em unidades de trabalho, e não de inversão de capital. Uma racionalidade econômica distinta da empresa capitalista em que os setores populares realizam, de modo individual ou familiar, modalidades de trabalho associativo, formalizados ou não. Nesse sentido, segundo Kraychete (2000, p. 15-16), denomina de economia dos setores populares: "cooperativas, empreendimentos autogestionários, oficinas de produção associada, centrais de comercialização de agricultores familiares, associações de artesãos, dentre outros".

A economia dos setores populares, de acordo com o autor acima referido, a não se confunde e nem se reduz a um âmbito do setor informal. E, ainda, não são iniciativas isoladas uma vez que interagem com seu entorno, com os mercados e circuitos produtivos dominantes. Argumenta que as condições de trabalho, necessárias à reprodução da vida de parcelas crescentes da população, não vêm sendo proporcionadas pelo mercado capitalista de trabalho, nem pelas ações compensatórias do Estado. Sua eficiência está na capacidade de gerar postos de trabalho e renda para um grande número de pessoas. Sua racionalidade está ancorada na lógica da necessidade do trabalho enquanto geração de renda para prover e repor os meios de vida da unidade familiar, e não na racionalidade econômica que visa o lucro e a acumulação do capital.

Já Laville e França Filho (2004) afirmam que a Economia Popular Solidária não é um fenômeno emergente, pois muitas de suas formas de ações coletivas e populares são antigas. Afirmam ainda que compreender a economia popular solidária exige outra concepção de economia, requer novos olhares, a partir de uma visão plural em que economia não se resume à economia de mercado; ela é mais ampla e interage em lógicas diferenciadas e sua ação organizacional quebra paradigmas da lógica hegemônica do capital. A economia popular solidária, na concepção de Laville e França Filho (2004), valoriza a dimensão pública de sua ação e seu impacto na organização local. Assim, esse agir no espaço público lhe confere uma dimensão política fundamental, que vai além de sua dimensão social e econômica. No entendimento desses autores, não se busca implantar uma outra economia e sim, pensar a economia solidária como um novo modo de agir no espaço público. Ou seja, a economia solidária enquanto uma ação política que provoca transformação institucional, valores coletivos e democráticos, cotidianamente construídos em diferentes contextos da realidade, possibilitando diferentes configurações dessas iniciativas. 
Para Arruda (2006), a economia popular solidária exige uma expansão planejada entre empresas e cooperativas solidárias, de modo a fomentar redes cooperativas e solidárias, de intercâmbio comercial, técnico, financeiro, cultural e afetivo, tecidas nos diferentes espaços. Enfatiza que com a democratização do poder político emergirá o protagonismo dos sujeitos e a construção de um Estado democratizado, cujo papel fundamental é estar a serviço da sociedade e fomentar o desenvolvimento humano e social na esfera local, nacional e global. Assim sendo, possibilitará o estabelecimento de limites para o crescimento econômico, valorizar-se-á a ética do cuidado e do suficiente e potencializará a educação para o autodesenvolvimento individual e coletivo, pautado em novos valores.

Nesse sentido, segundo Arruda (2006, p. 14), trata-se de um conceito que coloca a economia ligada à produção e à reprodução da vida, a serviço do humano e do social, tendo como qualificadores a autogestão e a solidariedade. Uma verdadeira revolução intelectual e moral na "sintaxe gramsciana", cuja relação de subjetividade torna o trabalhador sujeito de si e de sua história, tanto como indivíduo, como coletividade, articulado em redes cooperativas e solidárias, superando o velho sistema dominado pelo capital.

\section{OS CATADORES DE RECICLÁVEIS E A GESTÃO DOS RESÍDUOS SÓLIDOS}

A geração de Resíduos Sólidos Urbanos (RSU) têm sido um desafio e um dilema para o gerenciamento da limpeza urbana nos municípios brasileiros. Dados da Associação Brasileira de Empresas de Limpeza Pública e Resíduos Especiais (ABRELPE) apontam crescente produção de resíduos nas cidades brasileiras. Nesse sentido, Abrelpe (2015, p. 18 19) afirma que "por dia o brasileiro gera, em média, 1,071 quilos de lixo", e em 2015, o Brasil gerou 79,9 milhões de toneladas de resíduos sólidos. Em seu estudo sobre o Panorama dos Resíduos Sólidos no Brasil, argumenta que a população brasileira apresentou um crescimento de 0,8\% entre 2014 e 2015 e a geração per capita de resíduos sólidos urbanos cresceu no mesmo ritmo.

Conforme dados de Lajolo (2003), 90\% dos resíduos que chegam atualmente na indústria de reciclagem, passaram pelas mãos de catadores. Estes ao fazerem a limpeza urbana, procedem à coleta e a separação por classificação de materiais e os vendem a um intermediário que é o atravessador que irá vender para a indústria. Nesta mesma reflexão Medeiros \& Macedo (2005, p. 65), afirmam que "o comércio dos materiais recicláveis entre os catadores e as empresas de reciclagem geralmente passa pela mediação dos atravessadores. Esses intermediários recebem o material coletado pelos catadores, pesam e 
| Catadores de recicláveis reciclam processos organizativos, (re)significam o trabalho e constroem uma nova história|

| Renata Siviero Martins | Carlúcia Maria Silva |

estabelecem o preço a ser pago".

De acordo com Moura Fé e Faria (2011), os catadores estão inseridos em uma cadeia que é estruturada pela dinâmica do capital. Argumenta Pinhel (2013, p. 22) que a “indústria, ao comprar recicláveis, beneficia-se com economia de energia elétrica e matériaprima virgem, além da mão de obra para triagem”. Ainda nesta argumentação, Pinhel (2013, p. 17) sustenta que esses homens e mulheres há muitos anos lutam pela sua sobrevivência, fato este perceptível no crescente aumento da "presença de pessoas que vivem do comércio de materiais refugados", cuja presença, segundo este autor, "data do início do processo de industrialização".

Os catadores de recicláveis fazem parte do cenário das ruas de nossas cidades. Uma presença diária em busca da sobrevivência, muitas vezes adquirida no recolhimento e venda desses materiais recicláveis, que nós brasileiros geramos no nosso dia a dia. Homens e mulheres extremamente vulneráveis, vivendo em situação de exclusão social, política e econômica. Estudos realizados pelo Instituto de Pesquisa Econômica Aplicada (IPEA) demonstra o crescimento de catadores e catadoras nas ruas e avenidas das cidades. De acordo com IPEA (2013, p. 5), trata-se de "um grupo bastante numeroso de trabalhadores, tanto nas ruas quanto nos lixões, organizados ou não em cooperativas ou associações de catadoras e catadores, que sobrevivem muitas vezes em situação de vulnerabilidade social”.

A Fundação Avina, organização não governamental que tem como objetivos, promover o desenvolvimento sustentável e contribuir para mudanças concretas e relevantes para um desenvolvimento mais sustentável na América Latina, também vai nesta mesma direção, ao afirmar que "aproximadamente 15 milhões de pessoas, cerca de 1\% da população urbana nos países em desenvolvimento, obtém seu sustento diário no recolhimento de resíduos recicláveis". Outro dado importante, de acordo com Fundação Avina (2013, p. 1), é que, "no Brasil, existem 500 cooperativas de recicladores, que reúnem aproximadamente 60 mil pessoas".

A história dos catadores de materiais recicláveis envolve transformações relacionadas ao reconhecimento da função social do seu trabalho e de formas de organização coletiva. As primeiras associações e cooperativas de catadores de materiais recicláveis surgiram no Brasil no final da década de 80 e se multiplicaram posteriormente.

Quem nunca se deparou com um catador pelas ruas? Quem não se questionou ao ver um ser humano puxando um carrinho com tanto "lixo" ou revirando as lixeiras nas calçadas? Quem ainda não se perguntou quem é esta pessoa, se tem família, moradia e qual o sentido de ficar puxando um carrinho nos morros e vias das cidades? Esses trabalhadores 
são os que estão visíveis, pois ainda existem os que estão invisivelmente em lixões garimpando o lixo das cidades, como um modo também de produção de vida, de trabalho diário. Os catadores com o seu trabalho coletam o que para muitos é lixo, contribuindo com a limpeza urbana da cidade e gerando renda para sustentar seus familiares, ao recolher o que é jogado fora. Esses sujeitos evitam que sejam aterrados recursos naturais e os fazem retornar ao processo produtivo, como matéria prima secundária para as industriais e desta forma contribuem com o cuidado do meio ambiente e do futuro das gerações.

Desde 2010, ações e programas de fortalecimento do associativismo e cooperativismo de catadores de materiais recicláveis, voltados para a autogestão, assistência técnica e mobilização tem sido financiado pela Petrobrás. O Programa CATAFORTE I, II, e III, é uma promoção do Ministério do trabalho e emprego - MTE, via Fundação Banco do Brasil - FBB e, em Minas Gerais, tem sido executado pelo INSEA. Este Programa tem oportunizado a formação e capacitação para catadores e catadoras de recicláveis cooperados e nas ações desenvolvidas nos programas Cataforte, o Movimento Nacional de Catadores de Recicláveis (MNCR) tem sido uma presença efetiva.

Os objetivos principais deste Programa têm sido contribuir para uma maior inserção profissional, técnica, social e política dos participantes, além de fortalecer as organizações socioprodutivas de catadores de materiais recicláveis. Possibilitar espaços de proximidade, capacitação para a autogestão, assistência técnica, fomento à mobilização e intercâmbio entre as organizações de catadores são também outros objetivos a serem alcançados. Este trabalho com catadores, realizado em todas as regiões do país e em todo o estado de Minas Gerais, fortaleceu a participação de catadores associados e despertou nos participantes o comprometimento em relação aos catadores não associados, muitos dos quais realizam o trabalho da coleta de materiais recicláveis pelas ruas das cidades ou nos lixões.

É importante salientar que história organizativa desses trabalhadores e trabalhadoras tem seu marco no ano de 2001, quando aconteceu em Brasília o $1^{\circ}$ Congresso Nacional dos Catadores de Material Reciclável. Neste ano, 2001, foi fundado o Movimento Nacional dos Catadores de Materiais Recicláveis, que se institui como movimento político e social e cujo objetivo foi a organização e valorização dos catadores, garantindo o protagonismo destes sujeitos.

Nessa trajetória, pode-se dizer que esses homens e mulheres do "lixo", portadores de uma bagagem de saber adquirida no processo de conquista de sobrevivência da vida, com a instituição do MNCR se fortalecem e aprofundam coletivamente outros 
| Catadores de recicláveis reciclam processos organizativos, (re)significam o trabalho e constroem uma nova história|

| Renata Siviero Martins | Carlúcia Maria Silva |

conhecimentos, saberes e habilidades na luta pela conquista de direitos. Não se cansam da luta. Para Pinhel (2011, p. 27), “por sua história e capacidade de articulação, eles se fizeram presentes no debate sobre a Política Nacional de Resíduos Sólidos, que os aponta como parceiros preferenciais na gestão desses resíduos”. Nesta mesma direção Moura Fé \& Faria (2011, p. 25) ressaltam que “esse processo de organização social e política dos catadores é fruto especialmente de um profundo trabalho de base, de formação dos catadores, visando a sua organização e constituição enquanto sujeitos sociais e políticos”. As lutas e bandeiras levantadas por esses homens e mulheres reafirma a convicção de Freire (2000, p. 20), uma vez que "o discurso da impossibilidade de mudar o mundo é o discurso de quem, por diferentes razões, aceitou a acomodação, inclusive por lucrar com ela".

No dia a dia, os catadores vão construindo a seu modo diferentes práticas de saberes no trabalho. Para Freire (2000, p. 20), essas mulheres e homens "aprenderam que é aprendendo que se fazem e se refazem". Através da organização e das bandeiras de luta que vem travando ao longo desses anos, esses trabalhadores estão reconstruindo um novo modo de ler o mundo. Saindo da invisibilidade e lutando a cada dia pelo reconhecimento e respeito. Nas condições em que se encontram são permanentemente desafiados não somente a autogerir o empreendimento, mas também a assumir o controle da cadeia produtiva da reciclagem e por isso reafirmam a necessidade de criar e/ou fortalecer redes de comercialização, enquanto estratégia para melhorar a lucratividade e fugir dos atravessadores.

O trabalho destes sujeitos sociopolíticos, de acordo com os princípios da economia popular solidária, rompe com o paradigma de que esse país continue sendo de poucos. Não catam apenas material reciclado. Catam também vidas, dos outros e as próprias. Reciclam suas vidas e de outros companheiros. Reciclam sentidos. $O$ olhar para o que a sociedade descarta não é apenas econômico, mas também ressignificação.

As novas obrigações estabelecidas no nosso novo marco legal da gestão de resíduos sólidos urbanos, a partir da Lei № 12.305/10, proíbe o aterramento de resíduos orgânicos e recicláveis, o que reduzirá, sobremaneira, a necessidade de investimentos em aterros sanitários e no transporte de resíduos. A referida lei obriga, também, os produtores de materiais recicláveis - embalagens, eletroeletrônicos, pilhas, baterias, lâmpadas e outros a se responsabilizarem pela destinação final ambientalmente correta dos resíduos que geram por meio de processos de logística reversa e gestão compartilhada dos resíduos. Nesse sentido, vale salientar aqui a crescente consciência ambiental e sua preocupação em preservar os recursos naturais, reduzir o consumo, reutilizar, reciclar e reaproveitar, torna-se de fato o 
| Catadores de recicláveis reciclam processos organizativos, (re)significam o trabalho e constroem uma nova história|

| Renata Siviero Martins | Carlúcia Maria Silva |

melhor caminho para a busca de soluções ambientais. O problema do lixo não será resolvido com a melhor tecnologia, mas com a melhor organização.

\section{REFLEXÕES SOBRE A EXPERIÊNCIA DE CATADORES DE RECICLÁVEIS: o Projeto Novo Ciclo}

O Projeto Novo Ciclo foi iniciado em 2012 e suas ações decorreram da parceria entre três instituições - INSEA, MNCR e a Empresa DANONE BRASIL, que possui duas unidades industriais nesta região, tendo como referência o compromisso socioambiental da empresa e a responsabilidade compartilhada na gestão dos resíduos sólidos urbanos, conforme previsto na Política Nacional de Resíduos Sólidos (PNRS), Lei 12.305/10.

O tempo previsto para a execução do Projeto Novo Ciclo foi de quatro anos. E sob a coordenação do Instituto Nenuca de Desenvolvimento Sustentável (INSEA) e o Movimento Nacional dos Catadores de Materiais Recicláveis (MNCR), as ações realizadas partiram do diagnóstico e plano de ação realizado pelo Projeto Cataforte I, em 2010, e objetivaram o fortalecimento dos catadores de recicláveis, por meio de acompanhamento sistemático de suas associações e cooperativas.

As atividades envolveram a implantação e fortalecimento dos programas de coleta seletiva solidária, a capacitação de catadores e de técnicos municipais da região, educação ambiental e mobilização social, além da criação da rede de comercialização de material reciclável denominada Rede Sul Sudoeste MG. A criação desta rede representou um passo estratégico para consolidação do processo organizativo dos catadores da região. $\mathrm{O}$ conjunto dessas ações contou com um amplo processo formativo com catadores do Sul de Minas Gerais, além de um diagnóstico situacional dos empreendimentos. Um diagnóstico situacional sobre gestão de resíduos sólidos urbanos (RSU) nos municípios que integram a região também foi realizado, com a participação dos catadores, além de oficinas temáticas e visitas técnicas, tendo em vista subsidiar a elaboração de um Plano de Ação, no que diz respeito ao trabalho dos catadores.

É importante salientar que as atividades do Projeto Novo Ciclo foram realizadas em 23 municípios da Região Sul e Sudoeste de Minas Gerais e 27 empreendimentos de catadores foram acompanhados. A metodologia para execução deste Projeto foi a seguinte: considerando as distâncias geográficas dos municípios que seriam atendidos, estes foram divididos em três polos regionais, a saber, os municípios de Pouso Alegre, Poços de Caldas e Três Corações, tendo cada agrupamento de catadores de recicláveis, uma cidade polo como referência. Para permitir a troca de saberes, foram contratados técnicos sociais de 
áreas diferentes de conhecimento e catadores mobilizadores. Todas as ações técnicas e formativas foram compartilhadas entres estes profissionais, o que permitiu uma maior interação e também uma maior confiança dos catadores em suas organizações, pois este trabalho coletivo possibilitou falar a mesma linguagem dos catadores. Percebia-se confiança e credibilidade no processo formativo. Dessa forma dividiu-se a equipe de técnicos sociais e catadores em dupla para facilitar a mobilidade e o desenvolvimento do trabalho, sendo cada dupla responsável em implementar as ações nos municípios integrantes de cada um dos polos.

Nesses municípios, onde se desenvolviam os trabalhos com os catadores, foram firmados termos de cooperação técnica com gestores públicos, documento este em que se definiam contrapartidas e responsabilidades de cada parceiro. Dentre as ações previstas: implantação da coleta seletiva com inclusão dos catadores, infraestrutura necessária para coleta, capacitações e acompanhamento técnico dos catadores. Outra ação relevante foi a criação de um fórum gestor local, com participação com representantes do poder público, das organizações de catadores de recicláveis e da sociedade civil. Este fórum gestor local, teria o papel de discutir e construir coletivamente ações de preservação do meio ambiente, auxiliar na implantação de coleta seletiva e organização dos catadores. A criação do fórum gestor local possibilitou o debate e planejamento de todas as ações que envolveram o Projeto, além de articulações políticas importantes para o desenvolvimento de ações estratégicas na área de meio ambiente.

A partir da constituição do Fórum Gestor Local, o diagnóstico sobre a gestão de resíduos do município e sobre os catadores marcou a fase inaugural do Projeto. Este diagnóstico foi subdividido em três focos de coleta de dados: 1) a situação do município no que diz respeito à coleta seletiva e disposição final dos seus resíduos sólidos; 2) a organização produtiva dos catadores e infraestrutura necessária para coleta de recicláveis; e, 3) catadores em situação de rua e de lixão. É importante destacar que foram realizadas várias capacitações e acompanhamentos técnicos sistemáticos com os catadores associados nas associações e cooperativas integrantes do Projeto Novo Ciclo. Nessas atividades estiveram presentes os dirigentes dos empreendimentos de catadores e demais associados. Importante salientar também que em todas as atividades e capacitações realizadas a interação construída permitiu a troca de experiências entre os participantes.

$\mathrm{Na}$ avaliação dos catadores, os avanços são perceptíveis e a criação da Rede Sul Sudoeste MG ganha destaque nesta avaliação. Vale ressaltar aqui, que a criação de redes solidárias de cooperação foi uma pauta do Movimento da Economia Solidária e também do 
|Catadores de recicláveis reciclam processos organizativos, (re)significam o trabalho e constroem uma nova história|

| Renata Siviero Martins | Carlúcia Maria Silva |

programa Cataforte III, cujos resultados esperados, dentre outros, estava o fortalecimento de redes solidárias, nas quais se viabilizariam intercâmbio de experiências e a comercialização coletiva.

As redes solidárias de comercialização nasceram da preocupação da Secretaria Nacional de Economia Solidária (SENAES) e integram a Política Nacional de Economia Solidária, ou seja,

[...] diante deste panorama que inclui a expansão e consolidação da Economia Solidária na esfera pública nacional, um novo passo se faz necessário: a criação e/ou ampliação de Redes Solidárias de Cooperação com estruturas e ferramentas locais de planejamento e assessoramento técnico capazes de articular as iniciativas dos entes governamentais e da sociedade civil. Com isto se pretende promover a intersetorialidade e a integração entre as várias políticas públicas com vistas à construção coletiva de uma estratégia de desenvolvimento baseada no trabalho associado, no respeito ao meio ambiente e na justiça social (BRASIL, 2013, p. 2).

A articulação em rede, segundo Pinhel (2013, p. 22), significa um fortalecimento de suas Organizações, uma vez que a organização em rede possibilita várias ações coletiva e:

O mecanismo natural para atingir esse objetivo é a concentração da oferta de
materiais recicláveis em redes de organizações de catadores capazes de recuperar
uma quantidade considerável de material que lhes permita ter uma participação
importante no mercado, negociando assim preços e condições com as
indústrias.

Ao iniciar o projeto, os 23 municípios participantes se encontravam em situações das mais diversificadas: alguns deles apresentavam, como disposição final, o aterro controlado; outros, o aterro sanitário regularizado; e os demais, o lixão como disposição final. Em relação à existência de um programa municipal de coleta seletiva, menos da metade dos municípios possuíam coleta seletiva em parceria com os catadores e os outros não contavam com este serviço, ou seja, os catadores estavam realizando a coleta a sua maneira. Em relação à renda, um cenário de extrema precariedade, seja pelas condições de insalubridade inerentes ao trabalho nos lixões ou mesmo pela baixa remuneração destes trabalhadores. Outro aspecto a ser destacado é a relação com a sociedade civil. Na maioria dos municípios, uma grande parte da população desconhecia os catadores e o programa de coleta seletiva e com o Projeto foi possível criar um vínculo entre a sociedade civil, poder público e empreendimentos de catadores. Foram realizadas ações de mobilização social para a implantação e/ou revitalização dos programas de coleta seletiva, com a participação direta dos catadores que, levando panfletos, visitaram os moradores e sensibilizaram as pessoas a aderirem ao Projeto. Como resultado deste trabalho, a renda da maioria dos 
| Catadores de recicláveis reciclam processos organizativos, (re)significam o trabalho e constroem uma nova história|

| Renata Siviero Martins | Carlúcia Maria Silva |

catadores passou de meio salário mínimo para uma média de um salário ou um pouco mais.

Apesar dos inúmeros desafios, por exemplo, a autogestão e seus desdobramentos internos, há também desafios externos, como as ameaças de indústrias de incineração que oferecem aos municípios soluções rápidas para a gestão dos resíduos sólidos urbanos e a um "baixo" custo, além do fato de os gestores públicos não reconhecerem ainda o trabalho dos catadores. Alguns desses gestores públicos chegam a argumentar que esses trabalhadores e trabalhadoras já recebem muitas “ajudas” do Poder Público.

Ainda há muitos desafios a serem enfrentados, principalmente em relação à rede, que é uma grande esperança para os catadores, pois “mesmo se organizando para fugir da exploração econômica, o catador continua vulnerável a ela porque as indústrias que compram recicláveis são poucas e exigem grandes volumes para negociar" (IPESA, 2013, p. 23). Outro desafio é trabalhar a autogestão e o vínculo grupal, pois, como parte significativa dos catadores veio de lixões ou das ruas, a construção do vínculo coletivo e a gestão do próprio negócio precisam ser empoderadas pelos mesmos. No entanto, conforme aponta o IPEA (2013, p. 130), tais limites e desafios são compreensíveis, pois “juntos em cooperativas, os catadores deparam com uma realidade nova, na qual passam de subordinados a donos de um negócio, e isso não é nada fácil. Requer o desenvolvimento de diferentes competências necessárias à prática da gestão coletiva".

Pode se dizer que o Projeto Novo Ciclo foi importante para o fortalecimento dos empreendimentos de catadores e da parceria estabelecida, uma vez que, mesmo diante de alguns entraves encontrados nos municípios, a sinergia entre os envolvidos culminou num empenho mútuo em melhorar a vida destes trabalhadores e fazer com que a PNRS seja cumprida, ainda que parcialmente. Os resultados alcançados parcialmente apontam que ações conjuntas entre todos os atores do processo em torno de um mesmo objetivo produziram efeitos expressivos e que, principalmente a ação conjunta dentro dos Fóruns Municipais, acarretou em um maior compromisso da população em torno da coleta seletiva com inclusão dos catadores.

\section{CONSIDERAÇÕES FINAIS: confrontando conceito e experiência}

Nos últimos anos muito se tem discutido sobre a economia popular solidária. Estudos sobre essa temática têm possibilitado um importante debate teórico sobre sua natureza e definição. Muitas são as críticas em relação à confusão conceitual e teórica e às perversas ambiguidades entre esfera mercantil e não mercantil, sem contar o perigo do adestramento, bem como a necessidade de distinção entre uma economia de inserção de 
| Catadores de recicláveis reciclam processos organizativos, (re)significam o trabalho e constroem uma nova história|

| Renata Siviero Martins | Carlúcia Maria Silva |

caráter assistencialista e a economia propriamente solidária que, frente às injunções do mercado e dos poderes públicos, buscam garantir sua autonomia e preservar o projeto inicial.

A economia popular solidária apresenta uma diversidade quanto à sua organização, estruturação e institucionalização. Essas iniciativas socioeconômicas contam com a presença de segmentos sociais de baixa renda, sobretudo mulheres, fortemente atingidas pelo quadro de desocupação estrutural e empobrecimento. Essa diversidade desafiadora é perceptível no contexto nacional e suas diferentes regiões geográficas. Diferenças que se manifestam tanto no contexto nacional e suas distintas regiões geográficas, como também no que diz respeito ao plano econômico, político e cultural, permitindo, assim, uma complexidade de olhares.

O estudo feito apontou que a experiência do Projeto Novo Ciclo contribuiu na construção de processos de emancipação social, bem como oportunizou novos olhares, vivências e experiências. Constata-se também entre os envolvidos no Projeto disposição para o diálogo e trocas de saberes construídos no dia a dia do trabalho coletivo e da luta política. Percebe-se que as ações desenvolvidas por estes catadores envolvidos no Projeto Novo Ciclo têm propiciado experiências de resgate à cidadania e de apropriação sociopolítica sobre modos de vida e trabalho.

Pode-se dizer que estes homens e mulheres que ficam "escondidos" entre o "lixo", muitas vezes confundidos com o lixo, estão reciclando suas vidas e nesse exercício vivenciam o poder de livremente se expressarem, cujas opiniões são respeitadas e pesam no destino do coletivo neste movimento de reciclar e transformar vidas. Homens e mulheres, despertando para o importante papel que desempenham na sociedade, assumindo a luta contra opressões, discriminações, injustiças e desigualdades sociais, bem como lutas contra normas hierárquicas e arbitrárias.

Os processos organizativos e sociopolíticos desencadeados pelas organizações de catadores nos ajudam a pensar em um processo de conhecimento e construção coletiva que é acumulado de modo sistemático, indispensável para o processo de resistência. Nesse sentido, a potência presente nas práticas dos catadores deste Projeto nos convida a pensar a economia popular solidária e sua importância, bem como compreendê-la enquanto possibilitadora de mobilização e organização popular para o exercício do poder. Ainda nesta reflexão, esses processos educativos e sociopolíticos tornam-se também um convite a pensar e discutir o protagonismo dos sujeitos frente às transformações decorrentes.

Assim sendo, o que leva a apostar na economia popular solidária não é a relação 
construída com base na distinção e separação da lógica do modelo capitalista. Sua proposta tem como uma das principais metas a ampliação no usufruto das benesses do desenvolvimento, de modo que tais benefícios não se restrinjam apenas aos "capazes" de uma acumulação do capital e remete ao princípio basilar de organização da vida social e desenvolvimento material e humano. As relações de trabalho são definidas por regras mínimas, e a jornada de trabalho, salário e rateio do lucro são decididos coletivamente e as relações sociais estabelecidas. A construção da identidade e legitimação de uma "outra economia", sua abordagem sociológica e jurídica, são urgências colocadas para os empreendimentos econômicos solidários, bem como a discussão sobre solidariedade e eficiência em um contexto de desigualdade e concorrência muitas vezes desleal, sem contar o risco da reprodução do modelo de gestão capitalista.

Sem idealizar valores, nem dourar a pílula, a economia popular solidária tem a árdua tarefa de redescobrir a dimensão cidadã do trabalho e suas implicações políticas, econômicas e sociais, de modo que políticas públicas efetivas, direitos sociais e fortalecimento da cidadania sejam de fato seus princípios reguladores.

Por fim, esta "outra economia", a economia popular solidária, teimosamente desenvolvida pelos setores populares, aponta para um cenário desafiador, exigindo permanentemente um olhar atento, tendo em vista confrontar realidade e utopias, como também provocar a reflexão sobre limites, fragilidades, impasses e potencialidades que permeiam essa economia dos setores populares em tempos de globalização. Desvelar sua existência e sobrevivência, muitas vezes precária, dispersa e fragmentada, cuja viabilidade e crescimento têm sido colocados e exigem processos e ações convergentes e complementares entre os múltiplos sujeitos envolvidos.

\section{REFERÊNCIAS}

ARRUDA, Marcos. Globalização e Sociedade Civil: repensando o cooperativismo no contexto da cidadania ativa. Rio de Janeiro: PACS, 1996.

ARRUDA, Marcos. Tornar real o possível: a formação do ser humano integral, economia solidária, desenvolvimento e o futuro do trabalho. Rio de Janeiro: Vozes, 2006.

BARBOSA, Rosangela Nair de Carvalho. A Economia Solidária como política pública: uma tendência de geração de renda e ressignificação do trabalho no Brasil. São Paulo: Cortez, 2007.

BRASIL. Lei n ${ }^{\circ}$ 12.305, de 2 de agosto de 2010. Institui a Política Nacional de Resíduos Sólidos; altera a Lei no 9.605, de 12 de fevereiro de 1998; e dá outras providências. Diário Oficial da União, Brasília, 03 ago. 2010. Disponível em: 
|Catadores de recicláveis reciclam processos organizativos, (re)significam o trabalho e constroem uma nova história|

| Renata Siviero Martins | Carlúcia Maria Silva |

<http://www.planalto.gov.br/ccivil 03/ ato2007-2010/2010/lei/112305.htm> . Acesso em: 12 set.2013.

BRASIL/SENAES/MTE. Política Nacional de Economia Solidária. Termo de referência fomento às redes de cooperação solidárias, empreendimentos econômicos solidários organizados em cadeias produtivas e arranjos econômicos territoriais e setoriais de produção, comercialização e consumo sustentáveis e solidários. v. 3. Brasília: SENAES/TEM, 2013.2 Disponível em: $<$ http://trabalho.gov.br/images/Documentos/EconomiaSolidaria/orientacao/AcoesInteg radas16 jan. 2017.Redes.pdf>. Acesso em: 16 jan. 2017.

CATTANI, Antônio D. A outra economia: os conceitos essenciais. In: CATTANI, Antônio D. A. (Org.). A Outra Economia. Porto Alegre: Veraz. 2003a. p. 9-15.

FRANÇA FILHO, Genauto Carvalho de. Teoria e Prática em Economia Solidária: problemática, desafios e vocação. Civitas - Revista de Ciências Sociais, v. 7, n. 1, p. 155174, jan./jun. 2007.

FREIRE, Paulo. Pedagogia da Indignação. Cartas Pedagógicas e outros escritos. São Paulo: Editora UNESP, 2000.

FREIRE, Paulo; NOGUEIRA, Adriano. Que fazer: teoria e prática em educação popular. 4. ed. Petrópolis, RJ: Editora Vozes, 1989.

FRIGOTTO, Gaudêncio. A ideologia que embala a galinha dos ovos de ouro. In: TIRIBA, Lia; PICANÇO, Iracy (Org.). Trabalho e educação na Era do pós-emprego: arquitetos, abelhas e outros tecelões da economia popular solidaria. Aparecida, SP: Ideias \& Letras, 2004. p. 275-290.

FUNDAÇÃO AVINA. Reciclagem Inclusiva e Solidária. Disponível em: $<$ http://www.avina.net/por/oportunidades/reciclaje-inclusivo-y-solidario/>. Acesso em: 07 maio 2013.

GAIGER, Luiz Inácio. A Economia Solidária na contramarcha da pobreza. Sociologia, Problemas e Práticas, n. 79, p. 43-63, 2015.

GAIGER, Luiz Inácio. Sentidos e experiências da Economia Solidária no Brasil. Porto Alegre: UFRGS, 2004.

GAIGER, Luiz Inácio. Os caminhos da economia solidária no Rio Grande do Sul. In: SINGER, Paul; SOUZA, André Ricardo de (Org.). A economia solidária no Brasil. São Paulo: Contexto. 2000a, p. 267-286.

GAIGER, Luiz Inácio. Sentido e possibilidades da economia hoje. In: COSTA, Beatriz; KRAYCHETE, Gabriel; LARA, Francisco (Org.). Economia dos Setores Populares: entre a realidade e a utopia. Petrópolis: Vozes. 2000b. p. 167-198.

INSTITUTO DE PESQUISA ECONÔMICA APLICADA. Situação social das catadoras e catadores de materiais recicláveis e reutilizáveis. Brasília: IPEA, 2013a. Disponível

em: <http://www.ipea.gov.br/agencia/images/stories/PDFs/situacao social/131219 relatori 
| Catadores de recicláveis reciclam processos organizativos, (re)significam o trabalho e constroem uma nova história|

| Renata Siviero Martins | Carlúcia Maria Silva |

o situacaosocial mat reciclavel brasil.pdf>. Acesso em: 30 jan. 2017.

INSTITUTO DE PESQUISA ECONÔMICA APLICADA. Situação Social das catadoras e dos catadores de material reciclável e reutilizável (Região Sudeste). Brasília: IPEA, 2013b. Disponível em: <http://ipea.gov.br/portal/images/stories/PDFs/situacao social/130910 relatorio situa caosocial mat reciclavel regiaosudeste.pdf> . Acesso em: 30 jan. 2017.

KRAYCHETE, Gabriel. Economia dos Setores Populares: entre a realidade e a utopia. 2000. p. 1-19. Disponível em: < http://www.caritasbrasileira.org/textos/populares.pdf>. Acesso em: 30 jan. 2017.

LAJOLO, R. D. Cooperativa de Catadores de Materiais Recicláveis. Guia para implantação. CEMPRE - Compromisso Empresarial para a Reciclagem. São Paulo: IPT/SEBRAE, 2003.

LAVILLE, Jean-Louis; FRANÇA FILHO, Genauto de Carvalho. A Economia Solidária: uma abordagem internacional. Porto Alegre: UFRGS, 2004.

MEDEIROS, Luiza Ferreira Rezende de; MACÊDO, Kátia Barbosa. Catador de material reciclável: uma profissão para além da sobrevivência?. Psicologia \& Sociedade, v. 18, n. 2, p. 62-71 maio/ago. 2006. Disponível em: < http://www.scielo.br/pdf/psoc/v18n2/08.pdf>. Acesso em: 30 jan. 2017.

MOURA FÉ, Carlos Frederico Cerqueira de; FARIA, Maurício Sardá de. Catadores de resíduos recicláveis: autogestão, economia solidária e tecnologias sociais. In: ZANIN, Maria; GUTIERREZ, Rafaela Francisconi (Org.). Cooperativa de Catadores: reflexões sobre práticas. São Carlos: Clara Luz, 2011. p. 15-36.

PINHEL, J. R. O catador de materiais recicláveis. In: PINHEL, J. R (Org.). Do Lixo à Cidadania - Guia para a Formação de Cooperativas de Catadores de Materiais Recicláveis. São Paulo: Peirópolis, 2013. p. 27-27.

SINGER, Paul. Introdução à Economia Solidária. São Paulo: Ed. Perseu Abramo, 2002. 